\title{
Prevalence and risk factors of abdominal aortic aneurysm among over 65 years old population in Lublin, Poland
}

\author{
Jędrzej Tkaczyk', Stanisław Przywara², Michał Terpiłowski', Klaudia Brożyna', \\ Marek Iłżecki ${ }^{2}$, Piotr Terlecki ${ }^{2}$, Tomasz Zubilewicz ${ }^{2}$ \\ 'Students Scientific Group at the Department of Vascular Surgery and Angiology, Medical University of Lublin, Poland \\ ${ }^{2}$ Department of Vascular Surgery and Angiology, Medical University of Lublin, Poland
}

\begin{abstract}
Introduction: Abdominal aortic aneurysm (AAA) is a disease exceptionally well suited to screening. Ultrasound-based screening meets all criteria for a screening program according to the WHO, and there is a large evidence supporting its usefulness. Risk factors, mentioned in the available literature, associated with aneurysm formation are advanced age, male gender, tobacco smoking, hypertension, atherosclerotic disease and family or personal history of aortic aneurysms.

The aim of the study was to evaluate the incidence of abdominal aortic aneurysms in the population of men and women older than 65 years, in Lublin, Poland and to identify the correlation between risk factors and the AAA incidence.

Material and methods: A single-center screening study, for men and women older than 65-years was conducted in Lublin, Poland in May 20 18. Patients underwent basic screening ultrasound with measurement of the diameter of abdominal aorta and iliac arteries. Each patient completed anonymous questionnaire to investigate risk factors of developing AAA.

Results: 1032 patients, aged 65-91 (median age 71.37) were examined. 569 of them were women and 463 men. 27 aortic aneurysms were detected - 7 in a group of women and 20 in a group of men. The total incidence rate of AAA in our study was 2.62\%; 1,23\% in women and 4,32\% in men. Male gender, cigarette smoking, coronary artery disease and a history of myocardial infarction all appeared to be major risk factors of AAA, with relative risk ranging from 2,75 to 4.53 . The median diameter of the abdominal aorta was 19.24 $\mathrm{mm}$ and varied in groups of patients with different risk factors.

Conclusions: The estimated prevalence of AAA in the screened population is within the range of the values reported in previous publications, however, it may confirm a trend of declining prevalence of AAA showed in some recent studies. The presented study confirms the correlation between the AAA and its major risk factors (male sex, smoking cigarettes, coronary artery disease and history of myocardial infarct) as well as a weak association between AAA and hypertension and a negative correlation with diabetes.
\end{abstract}

Key words: abdominal aortic aneurysm, screening, ultrasound, vascular surgery

Acta Angiol 2019; 25, I: I-6

Address for correspondence: Jędrzej Tkaczyk, Students Scientific Group at the Department of Vascular Surgery and Angiology, Medical University of Lublin, Poland, e-mail: jedrzej.tkaczyk@gmail.com 


\section{Introduction}

Abdominal aortic aneurysm (AAA) is defined as dilatation of aorta diameter exceeding $30 \mathrm{~mm}$, or 1.5 times its original size or normal [ I]. The aortic segment, most commonly affected with AAA is the one below the ostia of renal arteries (infrarenal AAA). Only $5 \%$ of AAAs involves renal or visceral arteries [2]. The pathogenesis of AAA is mainly associated with atherosclerosis, which leads to a progressive weakening of the aortic wall [3]. AAAs demonstrate extensive structural remodelling, characterized by degeneration of extracellular matrix, destruction of elastic lamina and reduction of vascular smooth muscle cells (VSMCs) [4]. The involvement of inflammation in the pathogenesis of AAAs has been well recognized through the years. Inflammatory cells are responsible for the destruction of extracellular matrix and apoptosis of VSMCs, and are proposed to play a huge role in the development of AAA. The most commonly found in AAA tissues are CD4-positive lymphocytes or T cells, followed by B lymphocytes [5].

Risk factors, associated with aneurysm formation are advanced age, male gender, tobacco smoking, hypertension, atherosclerotic disease and family or personal history of aortic aneurysms [6, 7]. Dyslipidemia seems to be a weaker risk factor, while diabetic patients are at decreased risk for AAA [8]. According to available screening studies, the estimated prevalence of AAA ranges from $4.1 \%$ to $14.2 \%$ in men and from $0.35 \%$ to $6.2 \%$ in women [7]. However, some recent studies suggest a decrease in AAA prevalence: Svensjo et al. showed that the total prevalence of AAA in a population of 65 -year-old Swedish men was $2.2 \%$. A lower-than-expected prevalence of AAA, presented in this study, was probably caused by the observed reduced exposure to risk factors, especially smoking cigarettes [9].

In a natural history of AAA there is a long period of asymptomatic, subclinical increase in the diameter of the aneurysm, estimated at $<\mathrm{I}-6 \mathrm{~mm} /$ year $[\mathrm{I} 0, \mathrm{II}]$. The diameter progression depends on genetic and environmental factors - among which continued smoking and baseline diameter are the strongest factors for a rapid growth [II]. The risk of rupture rises with AAA maximal diameter and is higher in women than in men at similar diameters [I]. The estimated risk of death before the admission to the hospital in patients with AAA rupture is greater than $50 \%$, and $30-50 \%$ of those who were taken to the hospital and underwent aortic repair, would die during the postoperative period $[12,13]$. The most effective therapy to prevent death from aortic rupture is elective AAA repair [2].

AAA is a disease exceptionally well suited to screening [13]. Ultrasound-based screening meets all criteria for screening programs according to the $\mathrm{WHO}$, and there is substantial evidence supporting the usefulness of screening to detect $\mathrm{AAA}$ and thus reducing the risk of a death from AAA rupture in asymptomatic patients [13, 14]. There have been four large randomized controlled trials (RCT) between 1988 and 1999, that randomized male populations to ultrasound-based screening or no screening for AAA [15-18]. In these studies, a 40\% reduction in AAA related death has been demonstrated [19]. Moreover, the largest RCT — The Multicentre Aneurysm Screening Study, demonstrated a 3\% reduction in all-cause mortality after 13 years' follow up [15]. The studies, mentioned above, were the basis to start national screening programs in Sweden, the UK and the USA [20].

The purpose of the study was to evaluate the incidence of abdominal aortic aneurysms in the population of men and women older than 65 years in Lublin, Poland and to identify the correlation between risk factors and the AAA incidence.

\section{Material and methods}

Single-center, screening and prospective study, for men and women older than 65-years was conducted in Lublin, Poland in May 2018. Patients underwent colour Doppler ultrasound assessment and measurements of the diameter of the abdominal aorta (single measurement, in the segment below renal arteries) and iliac arteries. Each patient completed an anonymous questionnaire, regarding possible risk factors of developing AAA. Statistical analysis of the data was performed using the software Microsoft Excel, and STATISTICA I3.I. A p-value $\leq 0.05$ was considered as statistically significant. Relative risk assessment was used.

\section{Results}

1032 patients, aged 65-9l (median age 7l.37) underwent a social media call for ultrasound screening examination to detect AAA. 569 of them were women and 463 men (Table I). 27 aortic aneurysms (aortic diameter $>30 \mathrm{~mm}$ ) were detected -7 in a group of women and 20 in a group of men. The total incidence rate of AAA was $2.62 \%$. The incidence rate in women was $1.23 \%$ and in men $4.32 \%$.

The most common concomitant disease in the investigated population was hypertension - 631 patients (6I.I4\%). 206 patients (19.96\%) had coronary artery disease (CAD), and $20 \mathrm{I}$ patients suffered from diabetes (19.48\%). I I 8 of them (I2.98\%) admitted to smoke cigarettes. Among all of the risk factors history of myocardial infarction (MI) showed the strongest association with $A A A$; relative risk $(R R)=3.5 \mathrm{I}$. Prevalence of $A A A$ in 
Table I. Demographic data of the investigated population

\begin{tabular}{|l|c|c|c|c|c|}
\multirow{2}{*}{ Gender } & Number of Patients & \multicolumn{3}{c}{ Age } & Total number of patients \\
\cline { 3 - 5 } & & Minimum & Average & Maximum & \\
\hline Females & 569 & 65 & 70.97 & 89 & 1032 \\
\hline Males & 463 & 65 & 71.91 & 91 & \\
\hline
\end{tabular}

Table 2. Risk of developing AAA in groups of patients with or without risk factors

\begin{tabular}{|c|c|c|c|}
\hline \multirow[t]{2}{*}{ Risk factor } & \multicolumn{2}{|c|}{ Prevalence } & \multirow[t]{2}{*}{ Relative risk (RR) } \\
\hline & Yes & No & \\
\hline Smoking & $6.72 \%$ & $2 \%$ & 3.36 \\
\hline Hypertension & $2.69 \%$ & $2.49 \%$ & 1.08 \\
\hline Male sex & $4.32 \%$ & $1.23 \%$ & 3.51 \\
\hline Coronary artery disease & $5.34 \%$ & $1.94 \%$ & 2.75 \\
\hline Diabetes & $1.13 \%$ & $3.01 \%$ & 0.38 \\
\hline History of myocardial infarct & $8.33 \%$ & $1.84 \%$ & 4.53 \\
\hline
\end{tabular}

Table 3. Prevalence of risk factor in patients with or without AAA

\begin{tabular}{|c|c|c|c|}
\hline Risk factor & Patients with AAA & Patients without AAA & p-value \\
\hline Male sex & $74.07 \%$ & $44.08 \%$ & 0.001985 \\
\hline Smoking & $33.33 \%$ & $6.23 \%$ & 0.002257 \\
\hline Hypertension & $62.96 \%$ & $61.09 \%$ & 0.848114 \\
\hline Diabetes & $7.41 \%$ & $19.80 \%$ & 0.11577 \\
\hline Coronary artery disease & $40.74 \%$ & $19.40 \%$ & 0.008274 \\
\hline History of myocardial infarct & $25.93 \%$ & $8.66 \%$ & 0.000407 \\
\hline
\end{tabular}

a group of patients who had earlier a MI was $8.33 \%$, and only $1.84 \%$ for patients with no history of MI (Table 2). The second highest RR of developingAAA was observed for the male gender, comparing to women $(R R=3.36)$. The other risk factors that were associated with a higher risk of developing AAA were: smoking cigarettes $(R R=3.36)$ and $C A D(R R=2.75)$. Hypertension was not connected with a significant increase in the prevalence of AAA (RR = I.08), while diabetes appeared to be a potential factor decreasing the risk of developing $\mathrm{AAA}(\mathrm{RR}=0.38)$.

Among the patients with the AAA, 33,3\% were smokers, comparing to only $6,23 \%$ in a population without AAA ( $p=0.001985)$ (Table 3$)$. The other risk factors that were more often in patients with AAA were: male sex (74.07\% vs. $44.08 \% ; p=0.001985)$, CAD (40.74\% vs. 19.40\%; $p=0.008274)$ and history of $\mathrm{MI}(25.93 \%$ vs. $8.66 \%$; $=0.000407)$. All of these differences were statistically significant $(p<0.05)$. Hypertension was only slightly more often present in a group of patients with AAA $(62.96 \%)$ than in a group without $\mathrm{AAA}(6 \mathrm{I} .09 \%) ; p=0.848 \mathrm{I} \mid 4$, and this difference was not statistically significant $(p>0.05)$. On the contrary, diabetes was more frequent in a group without AAA, than with $\mathrm{AAA}$ (19.80\% vs. $7.41 \%$; $\mathrm{p}=$ 0.1 1577), however this difference was also not statistically significant $(p>0.05)$.

The median diameter of the aorta was $19.24 \mathrm{~mm}$, right iliac artery $10.84 \mathrm{~mm}$ and left iliac artery 10.90 $\mathrm{mm}$. The median diameter of aorta varied in groups of patients with different risk factors (Table 4), and it was the highest $(22.26 \mathrm{~mm})$ in group of patients with a history of $\mathrm{MI}$, which was 15,7\% more than the average diameter (19.24 mm) in an investigated group. On the contrary, the lowest diameter was registered in a group of patients with diabetes $(18,35 \mathrm{~mm}-4,63 \%$ less than the average for the investigated population).

Most of the AAAs (75\%) detected during the study were small - less than $45 \mathrm{~mm}$ (Table 5). AAAs with the diameter between 45 and $54 \mathrm{~mm}$ were observed in 
Table 4. The median diameter of abdominal aorta in groups of patients with or without different risk factors

\begin{tabular}{|l|c|c|}
\hline \multirow{2}{*}{ Risk factor } & \multicolumn{2}{c}{ The median diameter of aorta (in mm) } \\
\cline { 2 - 3 } & Yes & 17.72 \\
\hline Male sex & 21.20 & 19.11 \\
\hline Hyoking & 20.14 & 18.99 \\
\hline Diabetes & 19.42 & 19.42 \\
\hline Coronary artery disease & 18.35 & 18.93 \\
\hline History of myocardial infarct & 20.64 & 18.95 \\
\hline
\end{tabular}

Table 5. Distribution of the detected abdominal aortic aneurysms (AAAs) according to the maximum diameter

\begin{tabular}{|l|c|c|}
\hline Maximum diameter of AAA $($ in $\mathbf{~ m m})$ & No. of patients with AAA & 74.07 \\
\hline $30-44$ & 20 & 18.52 \\
\hline $45-54$ & 5 & 7.41 \\
\hline 55 and more & 2 & 100 \\
\hline Total & 27 & AAA \\
\hline
\end{tabular}

5 patients, which stated for $18.52 \%$. Aneurysms with the diameter equal or exceeding $55 \mathrm{~mm}$ were detected only in 2 patients (7.42\%).

\section{Discussion}

The study was conducted on the population of Lublin Voivodeship - a province, located in a southeastern Poland. It covers an area of 25, I 55 square kilometres, and the population is estimated at 2, I I 3 million people. The screening study took place in Lublin - the biggest city of the region (population estimated at 342,039 people). A screened group consisted mainly of citizens of Lublin, and nearest towns and villages.

The estimated prevalence of AAA in a presented population ( $4.32 \%$ in men and $1,23 \%$ in women) remains within the range of the values reported in previous publications [7]. Four biggest RCTs reported the prevalence of AAA in male populations at the level from $4 \%$ to $7.2 \%$ [15-18], however, some recent studies suggested changing epidemiology of AAA. The screening prevalence rates of $\mathrm{I} . \mathrm{I}-\mathrm{I} .7 \%$ have been recently reported $[9,2$ I ]. Our study seems to confirm that trend.

The presented study confirms that male sex, cigarette smoking, coronary artery disease and a history of myocardial infarction are all major risk factors for screening-detected AAA, with RR ranging from 2,75 to 4.53. Interestingly, though hypertension was the most frequent risk factor in a presented population, it did not appear to have a strong association with $A A A(R R=1.08)$.
Patients with diabetes seemed to have the lower risk of developing AAA (RR = 0.38). Similar correlations have been previously shown in earlier studies [7, 22].

A similar study, held in Poland from 2009 to $201 \mathrm{I}$ in the Kuyavian-Pomeranian Province by Jawien et al. [23] showed that the prevalence of AAA in the population of men aged 60 years and older was $6.0 \%$, which is higher than in our study. However, in this study, the prevalence of smoking cigarettes - one of the main risk factor of AAA - was also very high (55\%). The distribution of the detected AAAs according to the maximum diameter was similar to the one observed in our study [23].

An inverse association between diabetes mellitus and prevalence of AAA was shown already in previous studies [6, 7, 24], as well as the slower progression rates of AAAs in diabetic patients when compared to patients without diabetes $[25,26]$. Also, the results of meta-analysis of II studies, where the prevalence of DM in patients with AAAs ranged between 6 and $14 \%$, while in the absence of AAAs it was between 17 and $36 \%$ [27], correspond with our findings (7.41\% in patients with AAA; $19.8 \%$ in patients without AAA). However, the pathophysiological mechanisms for this negative relationship are still far from being defined [28]. The possible hypothesis includes increased arterial wall matrix formation via advanced glycation of end products; suppression of plasmin and reduction of levels and activity of matrix metalloproteinases MMP-2 and MMP-9; diminished aortic wall infiltration by macrophages, elastolysis and neovascularization [28-30]. 


\section{Conclusions}

Based on the obtained results, it is possible to state the following conclusions:

I. The prevalence of the AAAs in a population of $>65$ years old people in Lublin, Poland is within the range of the values reported previously in the literature.

2. Main risk factors associated with developing of AAA are constant with literature data and include male sex, smoking cigarettes, coronary artery disease and history of myocardial infarct.

3. Hypertension did not show a strong association with developing AAA.

4. The risk of developing of AAA appeared to be lower in patients with diabetes. The median aorta diameter of patients with AAA and diabetes was $4.63 \%$ lower than in a group without diabetes.

5. Prevalence of primary AAA risk factors: smoking cigarettes, CAD, history of MI, male sex was higher in a group with AAA than in a group without AAA. These differences were statistically significant.

6. Median aorta diameter in patients with risk factors or AAA development was higher than in patients without risk factors.

\section{Conflict of interest:}

None.

\section{References:}

I. Erbel R, Aboyans V, Boileau C, et al. Authors/Task Force members, ESC Committee for Practice Guidelines. 2014 ESC Guidelines on the diagnosis and treatment of aortic diseases: Document covering acute and chronic aortic diseases of the thoracic and abdominal aorta of the adult. The Task Force for the Diagnosis and Treatment of Aortic Diseases of the European Society of Cardiology (ESC). Eur Heart J. 2014; 35(4I): 2873-2926, doi: 10.1093/eurheartj/ehu28I, indexed in Pubmed: 25173340.

2. Jacob $A D$, Barkley PL, Broadbent KC, et al. Abdominal aortic aneurysm screening. Semin Roentgenol. 2015; 50(2): I18-126, doi: I0.1053/j.ro.20I4. 10.003, indexed in Pubmed: 25770342.

3. Guo DC, Papke CL, He R, et al. Pathogenesis of thoracic and abdominal aortic aneurysms. Ann NY Acad Sci. 2006; 1085: 339-352, doi: 10.1 196/annals. I383.013, indexed in Pubmed: 17182954.

4. Thompson RW, Liao S, Curci JA. Vascular smooth muscle cell apoptosis in abdominal aortic aneurysms. Coron Artery Dis. 1997; 8(10): 623-631, indexed in Pubmed: 9457444.

5. Shimizu K, Mitchell RN, Libby P. Inflammation and cellular immune responses in abdominal aortic aneurysms. Arterioscler Thromb Vasc Biol. 2006; 26(5): 987-994, doi: 10.1161/01. ATV.00002I4999.12921.4f, indexed in Pubmed: 16497993.

6. Lederle FA, Johnson GR, Wilson SE, et al. Prevalence and associations of abdominal aortic aneurysm detected through screening. Aneurysm Detection and Management (ADAM) Veterans Affairs Cooperative Study Group. Ann Intern Med. 1997; 126(6): 44|-449, indexed in Pubmed: 9072929.
7. Cornuz J, Sidoti Pinto C, Tevaearai H, et al. Risk factors for asymptomatic abdominal aortic aneurysm: systematic review and meta-analysis of population-based screening studies. Eur J Public Health. 2004; 14(4): 343-349, doi: 10.1093/eurpub/14.4.343, indexed in Pubmed: 15542867.

8. Golledge J, Muller J, Daugherty A, et al. Abdominal aortic aneurysm: pathogenesis and implications for management. Arterioscler Thromb Vasc Biol. 2006; 26(12): 2605-26I3, doi: 10.116I/0I. ATV.0000245819.32762.cb, indexed in Pubmed: 16973970.

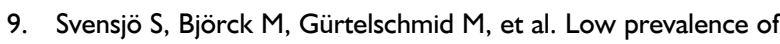
abdominal aortic aneurysm among 65-year-old Swedish men indicates a change in the epidemiology of the disease. Circulation. 201 I; 124(10): I I 18-1 I23, doi: 10.1 I61/CIRCULATIONAHA. I II.030379, indexed in Pubmed: 21844079.

10. Brady AR, Thompson SG, Fowkes FG, et al. UK Small Aneurysm Trial Participants. Abdominal aortic aneurysm expansion: risk factors and time intervals for surveillance. Circulation. 2004; IIO(I): 16-2I, doi: 10.1161/0I.CIR.0000133279.07468.9F, indexed in Pubmed: 15210603.

II. Badger SA, Jones C, McClements J, et al. Surveillance strategies according to the rate of growth of small abdominal aortic aneurysms. Vasc Med. 20II; 16(6): 4I5-42I, doi: 10.1 177//358863XI |42397।, indexed in Pubmed: 221 28040.

12. Mureebe L, Egorova N, Giacovelli JK, et al. National trends in the repair of ruptured abdominal aortic aneurysms. J Vasc Surg. 2008; 48(5): II0I-I 107, doi: 10.10I6/j.jvs.2008.06.03I, indexed in Pubmed: $1877 \mid 883$.

13. Bergqvist D, Björck M, Wanhainen A. Abdominal aortic aneurysm and new WHO criteria for screening. Int Angiol. 2013; 32(I): 37-4I, indexed in Pubmed: 23435390.

14. Lindholt JS, Norman P. Screening for abdominal aortic aneurysm reduces overall mortality in men. A meta-analysis of the mid- and long-term effects of screening for abdominal aortic aneurysms. Eur J Vasc Endovasc Surg. 2008; 36(2): 167-171, doi: 10.1016/j.ejvs.2008.03.006, indexed in Pubmed: 18485756.

15. Scott R. The Multicentre Aneurysm Screening Study (MASS) into the effect of abdominal aortic aneurysm screening on mortality in men: a randomised controlled trial. The Lancet. 2002; 360(9345): I53 I-1539, doi: 10.1016/s0|40-6736(02) | |522-4.

16. Scott R, Wilson NM, Ashton HA, et al. Influence of screening on the incidence of ruptured abdominal aortic aneurysm: 5-year results of a randomized controlled study. British Journal of Surgery. 1995; 82(8): 1066-1070, doi: 10.1002/bjs. 1800820821.

17. Norman P, Jamrozik K, Lawrence-Brown M, et al. Population based randomised controlled trial on impact of screening on mortality from abdominal aortic aneurysm. BMJ. 2004; 329(7477): I259, doi: 10.1 136/bmj.329.7477.1259.

18. Lindholt JS, Juul S, Fasting $\mathrm{H}$, et al. Hospital costs and benefits of screening for abdominal aortic aneurysms. Results from a randomised population screening trial. Eur J Vasc Endovasc Surg. 2002; 23(I): 55-60, doi: 10.1053/ejvs.200I.1534, indexed in Pubmed: 11748949.

19. Cosford PA, Leng GC. Screening for abdominal aortic aneurysm. Cochrane Database Syst Rev. 2007(2): CD002945, doi: 10.1002/14651858.CD002945.pub2, indexed in Pubmed: 17443519.

20. Stather PW, Dattani N, Bown MJ, et al. International variations in AAA screening. Eur J Vasc Endovasc Surg. 2013; 45(3): 23I-234, doi: 10.1016/j.ejvs.2012.12.013, indexed in Pubmed: 23332307. 
21. Hager J, Länne T, Carlsson P, et al. Lower prevalence than expected when screening 70-year-old men for abdominal aortic aneurysm. Eur J Vasc Endovasc Surg. 201 3; 46(4): 453-459, doi: 10.1016/j.ejvs.2013.07.014, indexed in Pubmed: 2397856 I.

22. Keisler B, Carter C. Abdominal aortic aneurysm. Am Fam Physician. 2015; 9I(8): 538-43.

23. Jawien A, Formankiewicz B, Derezinski T, et al. Abdominal aortic aneurysm screening program in Poland. Gefasschirurgie. 2014; 19(6): 545-548, doi: 10.1007/s00772-014-1348-4, indexed in Pubmed: 26120253.

24. Lederle F. The aneurysm detection and management study screening program. Archives of Internal Medicine. 2000; 160(10): 1425-1430, doi: 10.1001/archinte.160.10.1425.

25. Diehm N, Baumgartner I. Determinants of Aneurysmal Aortic Disease. Circulation. 2009; II9(16): 2134-2135, doi: 10.116I/ circulationaha. 109.850180.

26. Weiss JS, Sumpio BE. Review of prevalence and outcome of vascular disease in patients with diabetes mellitus. Eur J
Vasc Endovasc Surg. 2006; 3I(2): 143-150, doi: 10.1016/j. ejvs.2005.08.015, indexed in Pubmed: 16203161.

27. Shantikumar S, Ajjan R, Porter KE, et al. Diabetes and the abdominal aortic aneurysm. European Journal of Vascular and Endovascular Surgery. 2010; 39(2): 200-207, doi: 10.1016/j. ejvs.2009.10.014.

28. Pafili K, Gouni-Berthold I, Papanas N, et al. Abdominal aortic aneurysms and diabetes mellitus. J Diabetes Complications. 2015; 29(8): 1330-1336, doi: 10.1016/j.jdiacomp.2015.08.01 I, indexed in Pubmed: 26440573.

29. Golledge J, Karan M, Moran CS, et al. Reduced expansion rate of abdominal aortic aneurysms in patients with diabetes may be related to aberrant monocyte-matrix interactions. Eur Heart J. 2008; 29(5): 665-672, doi: 10.1093/eurheartj/ehm557, indexed in Pubmed: 18263873.

30. Norman PE, Davis TME, Le MT, et al. Matrix biology of abdominal aortic aneurysms in diabetes: mechanisms underlying the negative association. Connect Tissue Res. 2007; 48(3): I25-13I, doi: 10.1080/0300820070I33 I524, indexed in Pubmed: 17522995. 